\title{
Determinants and barriers of e-procurement: A European comparison of public sector experiences
}

\author{
Mila Gascó \\ University at Albany, SUNY \\ mgasco@ctg.albany.edu \\ Qianli Yuan \\ University at Albany, SUNY \\ qyuan@albany.edu
}

\author{
Maria Cucciniello \\ Bocconi University \\ maria.cucciniello@unibocconi.it
}

\author{
Greta Nasi \\ Bocconi University \\ greta.nasi@unibocconi.it
}

\begin{abstract}
Despite recent studies on determinants of adoption and diffusion of e-procurement, the existing literature is still scant on how different variables affect $e$ procurement adoption, diffusion and upscaling by type of adopter. Using qualitative data from interviews, this paper aims at contributing to fill this gap by examining how outer and inner variables influence the adoption and upscaling of e-procurement in two European regions that can be considered as innovators (Valencia in Spain and Lombardy in Italy). Our findings show that 1) the role of inner factors is clearer than that of outer ones in adoption processes, 2) in particular, organizational (mainly slack resources in both cases) and individual determinants seem to be the most important inner factors, 3) change management strategies and activities have a key role in upscaling processes, and 4) the internal organizational context and the type of technological innovation may act as moderators/mediators of the effects.
\end{abstract}

\section{Introduction ${ }^{1}$}

E-procurement, described as the use of ICT to automate and make more responsive and dynamic the purchasing process [8, 15], has become a growing innovation area in the public sector. Government

\footnotetext{
${ }^{1}$ The research leading to these results received funding from the European Union Seventh Framework Programme under grant agreement No. 320090 (Project Learning from Innovation in Public Sector Environments, LIPSE), Socioeconomic Sciences and Humanities. LIPSE is a research program under the European Commission's 7th Framework Programme as a Small or MediumScale Focused Research Project (2011-2014). The project focused on studying social innovations in the public sector (www.lipse.org).
}

agencies are more and more turning to e-procurement for the benefits it provides in terms of increasing transparency, lowering administrative costs and improving the economic outcome in a dynamic and competitive environment [25].

Recent studies have investigated which factors can possibly influence the adoption and diffusion of eprocurement $[4,12,25]$. However, the existing literature is still scant on how different variables affect e-procurement adoption, diffusion and upscaling by type of adopter (i.e. innovators, followers, late adopters, and laggards), although the theories on diffusion of innovation emphasize this issue [52].

In this paper, we aim at contributing to fill this gap by examining how outer and inner variables influence the adoption and upscaling of e-procurement in two European regions that can be considered as innovators (Valencia in Spain and Lombardy in Italy). Using qualitative data, our goal is to conduct a comparative analysis that will contribute to testing the veracity of the determinants and barriers emerged in the literature in the specific case of innovators/pioneers.

The remainder of this paper is organized as follows. In the next section, we present the literature on determinants and barriers of e-procurement. The data and methods used in our comparative analysis are then explained. Subsequently, we describe our case studies. Finally, we present the theoretical and practical implications of our findings and what further steps are to be taken.

\section{Literature Review: Determinants and barriers of e-procurement}

We started our study with a literature review of current research on influential factors to adopt and diffuse e-procurement. The review was developed according to the European project LIPSE. Online databases, such as Web of Science, JSTOR, Emerald, 
journals' and books websites, were employed to search relevant literature using key terms that combines egovernment/e-procurement, determinants/barriers and adoption/diffusion/upscale. Both empirical and theoretical studies published in English from international peer-reviewed journal articles, conference articles, books and other documents (e.g. reports) produced by the other European Union social innovation projects were analyzed. This review was conducted at two stages: April 2014 and March 2017. The first one reviewed 253 records published between 1970 and 2013. It developed the framework for influential factors in the project LIPSE. The second one looked for new papers published between 2014 and 2017 to improve the conceptual framework that guided this research. It paid special attention to literature about e-procurement in the public sector. The result is presented based on both literature reviews and intends to provide a conceptual framework to understand determinants and barriers for adopting and diffusing e-procurement.

A number of studies have discussed about key factors that could contribute or hinder the innovation cycle of certain types of ICT innovations in the public sector [16, 23]. This innovation cycle can be examined in three distinct phases-adoption, diffusion and upscaling [52]. Taking cognizance of previous studies and comprehensive reviews, a distinction is applied between determinants and barriers of the "outer" context and determinants and barriers of the "inner" context. Factors of the "outer" context refer to wider environmental factors and include inter-institutional dynamics, economic, political, social, demographic, and technological factors. Factors of the "inner" context are defined as characteristics that are intrinsically related to the organization and include organizational, individual, and technological factors. We argue that these different types of factors have different effects during the three phases of ICT-driven innovations in the public sector.

\subsection{Outer Context Factors}

2.1.1. Inter-institutional dynamics. Institutional isomorphism and mimicking is identified as an influential determinant in diffusion phases [18, 58]. This is noteworthy for late adopters, followers and laggards. Public organizations with similar stakeholders are subjected to the same environmental pressures, and therefore tend to choose similar behaviors to achieve a high level of legitimacy [56]. These dynamics often result in innovations clustering geographically [6]. The mimicking behavior can be caused by a competitive environment in the diffusion of ICT-driven innovations. Competition among provinces in China strongly motivates municipal agencies to mimic others' behaviors regarding government microblogging use for budget resources [37]. What these studies show is that governments do not want to lag behind neighbor and similar governments.

2.1.2. Economic factors. Economic factors are related to the wealth of the community involved in the adoption of ICT-driven innovations. A positive relationship is often found between healthy economic growth, increasing employment, strong fiscal capacity and ICT-driven innovations adoption [2, 38, 54] and diffusion [6]. Overall, state economic performance indicates sufficient state innovation capacity resources for social innovations [26]. It is also positively correlated with personal acceptance of ICT. Interestingly enough, the presence of budget constraints may trigger the innovation cycle of eprocurement. Cost savings brought by e-procurement stimulates public agencies with budget constraints to implement such systems $[1,8]$. However, unsuitable market structures and structural economic barriers (e.g. economies of scale, sunk costs) may impede the implementation of ICT-driven social innovations, especially in developing countries [48]. In this case, sustainable economic growth is critical for late adopters to keep sufficient fiscal resources [37].

2.1.3. Social factors. Social factors refer to the influential social attitude, norms and culture on stakeholders' perceptions and motivation [46]. Social norms play an important role in determining intentions of use. They capture the pressure of the social environment outside to behave normally [43]. Studies show that a risk-taking culture positively influences user's attitude and leads to behavioral intention toward e-procurement technologies. This may construct strong social expectations toward the introduction and diffusion of new technology [51, 63]. Strong public demands and citizens' awareness about the importance of e-procurement positively influence individual and organizational adoption decisions in developing countries [20, 37] but also require a high level of responsiveness from the government so as to further diffuse innovations [6, 63].

2.1.4. Political factors. Political factors refer to political attitudes, political regime structure, and legal and policy frameworks [5, 61]. Continuing political commitment helps to ensure sufficient resources and build a positive image of e-procurement to motivate public agencies [44, 53, 61]. A study [66] argue that the diffusion of e-government in U.S. states was more likely to occur when governors were institutionally powerful. Decentralized countries adopt e-government faster than centralized ones [21]. Recent studies in China also show that mandatory legislation may 
generate an upper-tier pressure, which is positively associated with adoption of ICT innovations [37, 67]. Strong political commitment and leadership styles play an important role to push late adopters [29]. However, conflicts in political priorities may act as barriers, deviating attention from e-procurement adoption [14, 48]. Rigid regulations could also reduce the flexibility and suffocate e-procurement innovations [30, 49].

2.1.5. Demographic factors. Demographic factors, in terms of population and education, are key in the innovation cycle [17, 45]. Jurisdictions with larger populations are more likely to adopt and diffuse ICTdriven innovations [28, 41, 42] as they have more slack resources. The study by [11] show population density in large and small cities matter more in diffusion of innovations. In addition to population size, population's level of education is also an important factor. Generally speaking, citizens with a higher level of education have a more positive perception of ICTdriven innovations, which facilitates the adoption process [3].

2.1.6. Technological factors. Technological factors refer to the contextual infrastructural capacity and level of general ICT readiness [22, 48]. A strong ICT infrastructural capacity enables adoption of ICT-driven innovation by government agencies [33]. It usually requires well-developed external network speed, connectivity and stability to ensure the operational performance of e-procurement. Another study [57] argue that municipalities in Turkey with a higher internet penetration rate were more prone to adopt edemocracy practices. System security and safety need to be ensured so that confidentiality breaches and opportunities for corruption can be avoided [49]. Citizens' ability to use the technology influences those initiatives' success [33]. Late adopters usually lag behind in terms of ICT readiness.

\subsection{Inner Context Factors}

2.2.1. Organizational factors. Organizational factors include the type, size, structure, processes, resources, capacities and mindset within a particular government agency. An innovation facilitating culture enhances recognition of benefits of new technologies, which may in turn promote adoption [7]. Some scholars [64] found that municipal governments with a risk-taking culture could overcome work routineness and personnel constraints. Usually, a risk-aversion culture in late adopters does not enable radical and systemic innovation [9, 31]. Organizational resources are essential to support sustainable adoption and diffusion. Higher operating budgets, IT staff availability and technical resources positively influence adoption at the local level [55]. Usually, large organizations are equipped with sufficient resources for long-term implementation of ICT-driven innovations [59]. Management capacity is, for example, required to reengineer business processes that will result in the integration of technology in the long term [34, 49]. However, late adopters usually lack resources and management capacity to support implementation of ICT-enabled innovations [39]. Therefore, leadership is critically important for late adopters since it is required to develop a feasible implementation strategy, to ensure sufficient resources and to transform managerial structures for ICT-driven innovations [35]. It is therefore important to encourage clear policies in the adoption of e-procurement in terms of budget, human resources, standard operating procedures, and technology. This also helps ICT-driven innovations to be adapted to the specific context and different needs of the imitating organization.

2.2.2. Individual factors. Individual factors are internal factors, which are related to individuals: ICTrelated perceptions, skills and capabilities of employees in government agencies [4, 12]. Perceptions of ICT-driven innovations, in terms of the ease of use and the perceived usefulness, motivates individuals to use particular ICT innovations and to follow prior users' experience [19, 32]. Only when employees are eager to accept the new technology, can that technology be actually implemented and adopted by the organization $[36,62]$. In addition, employees' ICT skills, such as their ability to use existing computers' applications and previous exposure to technology and networking, are also of great importance [22]. Besides ICT skills, individual communication and managerial skills are important to build networks among stakeholders [27]. Lack of ICT skills among late adopters is considered a barrier in the adoption of eprocurement.

2.2.3. Technological factors. Technological factors refer to usability, compatibility, and interoperability of information technology systems in the organizations. The quality and usability of technology itself could be highly influential to e-procurement adoption [2]. Eprocurement needs to match the goals, structure, and processes of an organization [60]. Government agencies need to build their systems in an interoperable way, which prevents serious technical problems of different specification integration [24, 49]. Some key features of suitable e-procurement systems are standardization, transparency, interactivity, accessibility, usability, privacy and reliability [47, 50]. Late adopters need to consider interoperability within their own organization as well as compatibility with uniform standards. Their internal low level of technological readiness, that is the characteristics and suitableness of the technology in government 
organizations, is usually very limited [7, 46]. Lack of strategic integration between different e-government systems has been identified as the primary obstacle to effectively implementing e-procurement [13].

From the above, we find that multiple determinants and barriers have an impact on e-procurement. Government agencies feel an implicit pressure to cluster with their "neighbors" and respond to citizens" demands, while they need to work at the organizational level to support adoption and diffusion of eprocurement. However, our literature review also reveals that, despite the existence of several studies that examine the effects of specific outer and inner factors on the adoption and diffusion of ICT-enabled innovations, the literature still largely lacks a) a comprehensive view of outer and inner factors that affect the adoption and diffusion of ICT-enabled innovations and $b$ ) both a systematic conceptualization and solid empirical evidence determinants of upscaling of ICT-enabled innovations. Overall, upscaling is conceptualized as a process that leads innovation to fully generate its social benefits through a homogeneous diffusion. Innovations are upscaled as long as they are recurrently and systematically used by the majority of potential adopters. This study will add the upscaling phase into the discussion, explore the effect of outer and inner influential factors on different phases and pursue a complete picture of determinants and barriers of e-procurement adoption, diffusion and upscaling for a specific type of adopters (the innovators).

\section{Research design}

Our study is motivated by the following research question: how do outer and inner variables influence the adoption and upscaling of e-procurement in the case of innovators?

The most appropriate way to address descriptive or explanatory research questions is through a qualitative case study [40]. Qualitative case studies are well suited to respond to 'how' and 'what' questions and allow us to study the research question in depth while leaving room for unexpected interesting findings that can form the basis for concrete hypotheses to be tested in future research [65]. In order to unpack the different drivers and barriers that play a role in the adoption, diffusion, and upscaling of e-procurement, we conducted a comparative case study that included the cases of the Autonomous Government of Valencia in Spain and the region of Lombardy in Italy. The cases were selected as part of a wider European project (LIPSE -Learning from Innovation in Public Sector Environments) that included a Work Package on ICT-driven innovations (e-procurement and telework). Further, the study of eprocurement in Europe is particularly interesting at the moment due to the legislative proposals to modernise European public procurement adopted by the European Commission in December 2011. Such proposals encouraged a gradual but ambitious transition towards e-procurement in the European Union by means of 1) making electronic means of communication mandatory by April 2016 for certain phases of the procurement process, 2) making e-submission mandatory for all contracting authorities and all procurement procedures by October 2018, and 3) adopting more detailed provisions to encourage interoperability and standardisation of e-procurement processes. These new legislative measures are putting a lot of pressure on member states, which have reacted heterogeneously to the European directives, adopting different eprocurement development models.

Eleven interviews were conducted with government officials involved in purchasing processes in both regions (five in Valencia and six in Lombardy) during November of 2014 using an interview protocol specifically developed for the study. The interviews focused on the institutional context, both the outer and inner determinants and barriers of adoption, and the determinants and barriers of upscaling. Interviews had an average duration of 60-75 minutes. All interviews were tape-recorded and transcribed for the purpose of the analysis. To increase data reliability, the interviewer reviewed and revised all transcriptions.

Interviews are being hand-coded line by line at the moment of writing, using a mixed inductive/deductive strategy, which entails using the existing literature to code data that matched existing concepts on ICTenabled innovation and e-government, while also remaining open to new codes emerging from the data, following a grounded theory approach (Glaser \& Strauss, 2009).

\section{Findings}

\subsection{Autonomous Government of Valencia (Spain)}

Valencia is one of the 17 Autonomous Communities that Spain has. It has around 4.9 million inhabitants (out of 46.7) and a GDP per capita of 21,200 Euros (the Spanish average is 24,500). Valencia is governed by the Autonomous Government of Valencia (Generalitat Valenciana). This regional public administration is divided into eight different departments. It is the Department of Finance and Public Administrations the one which is in charge of 
the Procurement Service that manages the eprocurement platform.

The e-procurement project is actually the result of another project: the implementation of the central purchasing body, regulated by the Decree 16/2012 (January 20). It was decided that the central purchasing body would use an electronic platform that would help to comply with the EU recommendations. The project had one main objective: efficiency, both in terms of money and simplified processes.

Vortal, one of the e-procurement leading companies, was contracted. They developed the platform (GE-Compras) in about six months. But, when the tool, was ready, they realized that they needed to regulate it. So, a legislative process started. It was fast but, still, it lasted one year and it resulted on the Decree 95/2013 (July 19).

The first electronic bid took place in February 2014 and had to do with the provision of electrical energy for the whole Autonomous Government of Valencia.

The Procurement Service is a small unit with only 7 employees and one director (the head of the service). Since the e-procurement platform is linked to the central purchasing body, it serves the whole Autonomous Government of Valencia (that is, the eight departments, the six autonomous entities, the 31 public sector organizations and the six fellow organizations). In this respect, it is important to notice that all these organizations have used the online platform during the information submission stage but only the central purchasing body uses the online platform for the rest of the process.

At the moment of the interviews, the Autonomous Government of Valencia had 18 suppliers out of which 8 operated electronically and used the e-procurement platform.

According to our interviewees, outer factors have hardly conditioned the implementation of eprocurement. Probably, political support was the most important determinant and was recognized as being positively influential although it was not thought to be as important as internal executive support (see below). In addition, two interviewees referred to the political will at the national level. E-procurement is a topic the national public administration in Spain was very focused on. So, in a way, this has seemed to slightly contribute to "sell" the project internally.

Inner factors have been much more significant. In particular, organizational factors have had a strong impact. Our interviewees referred to the negative effect of slack resources (economic, material, and human), organizational culture (the Generalitat Valenciana is not believed to be an innovative public organization), and resistance to change (which is also the result of individual factors, basically the lack of clarity to individuals about the benefits of the project). However, they also mentioned managerial leadership and support as being crucial. There was agreement on the fact that the project was (very well) led by the undersecretary of Finance and Public Administrations, which is considered the first executive position in the administrative structure. Further, the head of the Procurement Service has played a decisive role. She is the one who really knows about e-procurement. She really believes in the project and she is very convinced of its benefits despite the risks it also entails. From a technological perspective, the organization was ready to implement e-procurement. However, several interviewees complained about connections being extremely slow or platforms not being as intuitive as needed.

Finally, the upscaling process seems to still be limited in scope. Legal constraints appear to be an important determinant in this process. So does (the lack of) interoperability and the organizational inertia and/or resistance. According to one of our responders, "there will be resistance in the upscaling process. On one hand, the expansion to the different procurement units in the Autonomous Government of Valencia is an expensive process from an economic point of view. But, on the other, changes in the public administration result in tensions. They cause nervousness, uncertainty. And we are a very conservative organization".

\subsection{Region of Lombardy (Italy)}

Lombardy is one of the twenty administrative regions of Italy, in the northwest of the country, with an area of 23,844 square kilometres (9,206 sq mi). 10 million people, forming one-sixth of Italy's population, live in Lombardy and about a fifth of Italy's GDP is produced in the region, making it the most populous and richest region in the country and one of the richest regions in Europe.

A central purchasing body for the whole regional system, fully owned by the regional government, was created in April 2014. The public company is thus a public service provider that intermediates the relationships between public service organizations (PSOs) and actual or potential providers. In the Italian context, the e-procurement experience of Lombardy can be considered an eminent case of early adoption.

In the Lombardy case, the role of inter-institutional dynamics has been positively influential for the establishment of a central purchasing body in the regional government. One interviewee has remarked the role of international best practices as relevant parameters for the very first adoption. Another interviewee recognizes the existence of a positive competition among regions. Lombardy has the 
reputation of being an "innovative region", and the fact that there was an e-procurement platform at the national level has generated the will to do "even better". E-procurement represents indeed a flagship initiative for the regional government.

Law is probably the most influential exogenous factor in driving the adoption of e-procurement. The new Public Procurement Code (Codice dei Contratti Pubblici in Italian) has harmonized the national legislative framework with the European Union Directives on Public Procurement. Moreover, the Finance Law of 2007 has enabled Italian regions to autonomously establish central purchasing bodies. However, the strongest measure to promote eprocurement was enforced in 2012 through the socalled Spending Review, which also obliges local authorities to conduct most of their procurement procedures through the available central purchasing bodies.

The decision of the regional government to establish a central purchasing body was mainly driven by a solid and long-lasting vision on the potential of eprocurement. This has resulted in continuous support to the project. As underlined by one of the interviewees, political stability in supporting eprocurement beyond the electoral cycle was a powerful positive determinant.

The diffused culture of quality and innovation within institutions has certainly facilitated the emergence of Lombardy as an early adopter. Nonetheless, economic operators have sometimes shown opposite attitudes. Some providers have a culture of manual skills, which results in reluctance towards innovative instruments for doing business. As underlined by one interviewee, there is a need to raise the awareness of benefits vis-à-vis stakeholders, so to explain how e-procurement can enhance their opportunities in competitive bids.

According to the interviewees, economic factors have positively influenced the adoption of eprocurement. Lombardy is among the wealthiest and more industrialized regions in Italy. This results in relevant fiscal capacities for investing in innovation.

The sophistication of regional ICT infrastructures has also facilitated the adoption and diffusion of eprocurement. According to one interviewee, a slight territorial divide of certain peripheral areas may have represented a barrier when e-procurement was firstly launched, but such differences are now virtually nonexistent

Looking at the "inner" context, governance arrangements of the central purchasing body deserve to be taken into account while analyzing the organizational environment. One interviewee referred to the numerous changes in governance arrangements as an important barrier. Not just autonomy, but also organizational slacks (in terms of money, human resources and infrastructures) facilitate the upscaling of e-procurement. Interviewees also noticed that larger PSOs face greater barriers for adoption because of their institutional complexity.

All the interviewees agreed on the influence of personal characteristics: within the public company, employees were mainly young and high-skilled professionals. Moreover, they had considerable autonomy to express their creativity. This facilitates the diffusion of e-procurement: the adoption of eprocurement is more likely if such actors are young, well-educated and digital native. Past experiences in the private sector (e.g. consulting, ICT companies) are also relevant. Long-serving employees can be positively influential as well, as long as they have an in-depth knowledge of organizational processes and a positive attitude towards change. Such pioneers often act as bottom-up promoters of adoption within PSOs.

Technological factors, such as the internal ICT infrastructure, are mainly considered as not influential. For example, one interviewee acknowledged that local governments are not provided with up-to-date technological equipment. Yet, local governments have been able to work towards adoption of e-procurement.

Finally, during the interviews, upscaling processes were mainly conceptualized in terms of e-procurement extension among the numerous PSOs and their various policy fields. Interviewees agreed in attributing a critically positive role to consulting and training activities. The underlying belief was that technology is not a "panacea" per se, but as long as it supports organizational processes. This requires a constant effort in delicately persuading potential users while providing the usual support to those that are already adopters. Various projects to further upscale eprocurement are now under evaluation (e.g. tutorials, sophisticated FAQs database, permanent help desks in the territories, large-scale network of best practices).

\section{Comparative analysis and conclusions}

Table 1 compares the cases of Valencia and Lombardy.

Table 1. Determinant of e-procurement adoption and upscaling: Comparing the regions of Valencia (Spain) and Lombardy (Italy)

\begin{tabular}{|l|l|l|}
\hline & \multicolumn{1}{|c|}{ Valencia } & \multicolumn{1}{c|}{ Italy } \\
\hline Outer context & \multicolumn{2}{|c|}{} \\
\hline $\begin{array}{l}\text { Inter-institutional } \\
\text { dynamics }\end{array}$ & No influence & $\begin{array}{l}\text { Positive } \\
\text { influence of } \\
\text { international } \\
\text { best practices }\end{array}$ \\
\hline
\end{tabular}




\begin{tabular}{|c|c|c|}
\hline & & and competition \\
\hline $\begin{array}{l}\text { Economic } \\
\text { factors }\end{array}$ & No influence & $\begin{array}{l}\text { Positive } \\
\text { influence of } \\
\text { wealth and fiscal } \\
\text { capacities }\end{array}$ \\
\hline Social factors & No influence & $\begin{array}{l}\text { Negative } \\
\text { influence } \\
\text { economic } \\
\text { operators' } \\
\text { perceptions }\end{array}$ \\
\hline Political factors & $\begin{array}{l}\text { Positive } \\
\text { influence } \\
\text { political of } \\
\text { leadership }\end{array}$ & $\begin{array}{l}\text { Positive } \\
\text { influence of } \\
\text { legislation and } \\
\text { political stability }\end{array}$ \\
\hline $\begin{array}{l}\text { Demographic } \\
\text { factors }\end{array}$ & No influence & No influence \\
\hline $\begin{array}{l}\text { Technological } \\
\text { factors }\end{array}$ & No influence & $\begin{array}{l}\text { Positive } \\
\text { influence of } \\
\text { sophisticated } \\
\text { regional ICT } \\
\text { infrastructures }\end{array}$ \\
\hline \multicolumn{3}{|l|}{ Inner factors } \\
\hline $\begin{array}{l}\text { Organizational } \\
\text { factors }\end{array}$ & 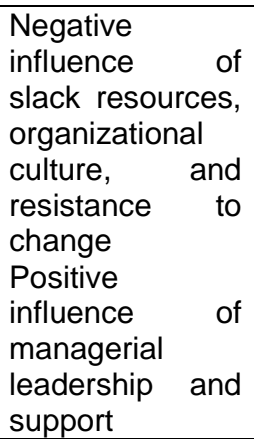 & $\begin{array}{l}\text { Negative } \\
\text { influence } \\
\text { governance of } \\
\text { arrangements } \\
\text { (autonomy, } \\
\text { slack resources) } \\
\text { and institutional } \\
\text { complexity }\end{array}$ \\
\hline $\begin{array}{l}\text { Individual } \\
\text { factors }\end{array}$ & $\begin{array}{l}\text { Negative } \\
\text { influence } \\
\text { perceptions of } \\
\text { lack of clarity } \\
\text { about } \\
\text { project }\end{array}$ & $\begin{array}{l}\text { Positive } \\
\text { influence young } \\
\text { and high-skilled } \\
\text { professionals }\end{array}$ \\
\hline $\begin{array}{l}\text { Technological } \\
\text { factors }\end{array}$ & $\begin{array}{l}\text { General positive } \\
\text { influence of } \\
\text { technological } \\
\text { readiness } \\
\text { Slightly negative } \\
\text { influence of lack } \\
\text { of connectivity }\end{array}$ & No influence \\
\hline
\end{tabular}

Although both regions can be considered as innovators, interestingly enough, the factors that have determined adoption and upscaling of e-procurement are quite different. To start with, in the case of Valencia, the important set of factors are the inner ones. External or outer variables have hardly influenced adoption of e-procurement. Only political factors seem to be relevant in both cases. In particular, political support beyond the electoral cycle is a powerful positive determinant, such as previous works also show [29, 44, 53, 61]. Further, demographic factors do not seem to have any impact. This is probably related to the type of technological project we are analyzing: citizens are not important stakeholders in e-procurement initiatives and, therefore, their influence on adoption and upscaling decisions is very limited.

Our comparison shows that internal factors play an important role in both cases. Organizational variables have a negative influence in the two regions. However, the specific types of organizational variables differ. In the Autonomous Government of Valencia, the organizational culture and resistance to change are very relevant factors. This is an interesting finding for the literature shows that a risk-aversion culture can be more often found within late adopters than innovators $[9,31]$. Actually, the interviewees from the region of Lombardy did not report organizational culture as a negative determinant. Governance arrangements and institutional complexity seem to be more important variables in the region of Lombardy. The literature has not sufficiently addressed how the structure and internal processes might hinder e-procurement adoption and upscaling. Thus, this is an area that needs further attention.

Individual factors also play a role in the adoption of e-procurement but, as with organizational variables, eprocurement is influenced by different individual factors in each of the regions. In the case of Valencia, individual perceptions of the project are key $[19,32]$ whereas personal attributes and skills are of greater influence in the case of Lombardy [22, 27].

Finally, both regions seem to be struggling with upscaling processes, which seem to be conditioned by individual and organizational skepticism. In the case of Valencia, upscaling has not even started but interviewees foresaw important barriers in relation to the organizational inertia and resistance to change. In the case of Lombardy, upscaling has only be conceptualized but a few training and consulting initiatives (believed to have a positive influence on the process) have been put in place. Interestingly enough, in both cases, interviewees recognized the importance of change management strategies and activities.

In light of this comparison, we can conclude that, in the case of adoption and upscaling of e-procurement by innovators:

- The role of inner factors is clearer than that of outer ones.

- Political commitment and support are key. There is a need for political leaders, willing to innovate and, therefore, to take risks.

- The type of technological innovation (eprocurement in this particular case) determines the influence of certain outer factors, such as the demographic ones. 
- Organizational and individual determinants seem to be the most important inner factors. Interestingly enough, different organizations face different circumstances and, therefore, put more stress on dissimilar types of organizational and individual factors. Thus, we can infer that the internal context of organizations matters. Further research is needed to have more clarity on how context may mediate the influence of organizational and individual variables in the adoption and upscaling of e-procurement.

- Slack resources are of great importance. Although this factor has usually been linked to late adopters, our research shows that innovators do also experience challenges in this respect.

- There is no clarity on the determinants of the upscaling of e-procurement. This is mainly due to the fact that upscaling is only timidly taking place. Yet, our research shows that, at least, change management strategies and actions need to be implemented for the upscaling process to be successful.

Our study also shows that more in-depth research is needed in this field, and particularly, in relation to upscaling processes. We aimed at exploring the determinants of adoption and upscaling of eprocurement by innovators. Yet, we found important differences in the processes undertaken by each of the two pioneering regions. We thus plan to expand the sample horizontally using the data collected by LIPSE researchers and introducing in our analysis moderators/mediators, such as internal context and type of technological innovation.

\section{References}

[1] Adebiyi, A. A., Ayo, C. K., and Adebiyi, M. O., "Development of Electronic Government Procurement (e-GP) System for Nigeria Public Sector", International Journal of Electrical \& Computer Sciences IJECSIJENS, 10, 6 (2010), pp. 69-76.

[2] Ahn, M. J., "Adoption of E-Communication Applications in U.S. Municipalities: The Role of Political Environment, Bureaucratic Structure, and the Nature of Applications". The American Review of Public Administration 41, 4 (2011), pp. 428-452.

[3] Al, A. A. A. R. A., "Demographic factors as determinants of e-governance adoption", Transforming Government: People, Process and Policy, 9, 2 (2015), pp. 159.

[4] Altayyar, A., and Beaumont-kerridge, J., "External Factors Affecting The Adoption of E-procurement in Saudi Arabian's SMEs", Procedia - Social and Behavioral Sciences, 229 (2016), pp. 363-375.
[5] Ask, A., Hatakka, M., and Grönlund, Å., "The Örebro city citizen-oriented e-Government strategy", Social and Organizational Developments through Emerging E-Government Applications: New Principles and Concepts: New Principles and Concepts (2009), pp. 233.

[6] Bhatti, Y., Olsen, A. L., and Pedersen, L. H., "Administrative professionals and the diffusion of innovations: The case of citizen service centres", Public Administration, 89, 2 (2011), pp. 577-594.

[7] Bof, F. and Previtali, P., "Organisational pre-conditions for e-procurement in governments: the italian experience in the public health care sector", The Electronic Journal of e-Government, 5, 1 (2007), pp. 110.

[8] Bof, F., and Previtali, P., "National models of public (e)-procurement in Europe", Journal of e-Government Studies and Best Practices, 2010, 315295 (2010), pp. 114.

[9] Borins, S. (eds.), Innovations in Government: Research recognition and replication, Washington: Brookings Institute, 2008.

[10] Boughzala, I., and Briggs, R. O., "A value frequency model of knowledge sharing: an exploratory study on knowledge sharability in cross-organizational collaboration", Electronic Markets, 22, 1 (2012), pp. 919.

[11] Brudney, J. L., and Selden, S. C., "The adoption of innovation by smaller local governments: The case of computer technology", The American Review of Public Administration, 25, 1 (1995), pp. 71-86.

[12] Choi, H., Jae, M., Jeung, J., and Zo, H., "Rethinking the assessment of e-government implementation in developing countries from the perspective of the design - reality gap: Applications in the Indonesian eprocurement system", Telecommunications Policy, 40, 7 (2016), pp. 644-660.

[13] Cimander, R., Hansen, M., and Kubicek, H., "Electronic Signatures as Obstacle for Cross-Border EProcurement in Europe: Lessons from the PROCUREproject", Institute for Informations Management Bremen GmbH (ifib) (2009).

[14] Considine, M, Lewis, JM, and Alexander, D., Networks, innovation and public policy: Politicians, bureaucrats and the pathways to change inside government. Basingstoke UK: Palgrave Macmillan, 2009.

[15] Coulthard, D. and Castleman, T., "Electronic procurement in government: more complicated than just good business", Bled, Slovenia, 1, 3 (2001), pp. 999-1009.

[16] Cucciniello, M., Nasi, G., Mele, V., Valotti, G., and Bazurli, R., "Determinants and Barriers of Adoption, Diffusion and Upscaling of ICT-driven Social Innovation in the Public Sector : A Systematic Review", 6, (2015).

[17] de Guzman, M. C., and Jones, M. A., "E-Policing: Environmental and organizational correlates of website features and characteristics among large police departments in the united states of america", 
International Journal of Electronic Government Research (IJEGR), 8, 1 (2012), pp. 64-82.

[18] DiMaggio, P., and Powell, W. W., "The iron cage revisited: Collective rationality and institutional isomorphism in organizational fields", American Sociological Review, 48, 2 (1983), pp. 147-160.

[19] Elbanna, A., "From intention to use to actual rejection: the journey of an e-procurement system", Journal of Enterprise Information Management, 23, 1 (2010), pp. 81-99.

[20] Gamal Aboelmaged, M., "Reconstructing Six Sigma barriers in manufacturing and service organizations: The effects of organizational parameters", International Journal of Quality \& Reliability Management, 28, 5 (2011), 519-541.

[21] Gascó, M. Esteve, M. and Fernández, C., "Managing E-Government Interoperability: Abandoning Projects to Develop Real Management Models", Paper presented at the 11th Public Management Research Conference, Madison, Wisconsin, June 20th-22nd, 2013.

[22] Ghani, E. K., and Said, J., "Digital reporting practices among Malaysian local authorities", Electronic Journal of e-Government, 8, 1 (2010), pp. 33-44.

[23] Greenhalgh, T., Robert, G., Macfarlane, F., Bate, P., and Kyriakidou, O., "Diffusion of innovations in service organizations: systematic review and recommendations", Milbank Quarterly, 82, 4 (2004), pp. 581-629.

[24] Gunasekaran, A., and Ngai, E. W., "Adoption of eprocurement in Hong Kong: an empirical research", International Journal of Production Economics, 113, 1 (2008), pp. 159-175.

[25] Gurakar, E. C., and Tas, B. K. O., "Does Public EProcurement Deliver What It Promises? Empirical Evidence from Turkey", Emerging Markets Finance and Trade, 52, 11 (2016), pp. 2669-2684.

[26] Hall, J. L., "Informing state economic development policy in the new economy: A theoretical foundation and empirical examination of state innovation in the United States", Public Administration Review, 67, 4 (2007), pp. 630-645.

[27] Hardy, C. A., and Williams, S. P., "E-government policy and practice: A theoretical and empirical exploration of public e-procurement", Government Information Quarterly, 25, 2 (2008), pp. 155-180.

[28] Huang, Z., "A comprehensive analysis of US counties' e-Government portals: development status and functionalities", European Journal of Information Systems, 16, 2 (2007), pp. 149-164.

[29] Huntgeburth, J. C., Steininger, D. M., Parasie, N. P., and Veit, D. J., "Increasing the adoption of eprocurement services at the municipal level", e-Service Journal, 8, 3 (2012), pp. 3-23.

[30] Jaeger, P. T., "Constitutional principles and EGovernment: an opinion about possible effects of Federalism and the separation of powers on EGovernment policies", Government Information Quarterly, 19, 4 (2002), pp. 357-368.

[31] Janssen, M., "Sociopolitical aspects of interoperability and enterprise architecture in e-government", Social Science Computer Review, 30, 1 (2012), pp. 24-36.
[32] Jung, C. S., and Lee, G., "Organizational Climate, Leadership, Organization Size, and Aspiration for Innovation in Government Agencies", Public Performance \& Management Review, 39, 4 (2016), pp. 757-782.

[33] Karunasena, K., and Deng, H., "A citizen-oriented approach for evaluating the performance of egovernment in sri lanka", International Journal of Electronic Government Research (IJEGR), 8, 1 (2012), pp. 43-63.

[34] Kim, W., Kim, S. D., Lee, E., and Lee, S., "Adoption issues for cloud computing", In Proceedings of the 7th International Conference on Advances in Mobile Computing and Multimedia (pp. 2-5) (2009, December). ACM.

[35] Korteland, E., and Bekkers, V., "Diffusion of Egovernment innovations in the Dutch public sector: The case of digital community policing", Information Polity, 12, 3 (2007), pp. 139-150.

[36] Li, M. H., and Feeney, M. K., "Adoption of electronic technologies in local US governments: Distinguishing between e-services and communication technologies", The American Review of Public Administration, 44, 1 (2014), pp. 75-91.

[37] Ma, L., "Diffusion and assimilation of government microblogging: Evidence from Chinese cities. Public Management Review, 16, 2 (2014), pp. 274-295.

[38] Manoharan, A., "A Study of the Determinants of County E-Government in the United States", American Review of Public Administration 43, 2 (2013), pp. 159178.

[39] Maranto, R., and Wolf, P. J., "Cops, teachers, and the art of the impossible: Explaining the lack of diffusion of innovations that make impossible jobs possible", Public Administration Review, 73, 2 (2013), pp. 230240.

[40] Marshall, C., and Rossman, G. B., Designing qualitative research, Sage, 2011.

[41] Moon, M. J., "The evolution of e-government among municipalities: rhetoric or reality?", Public administration review, 62, 4 (2002), pp. 424-433.

[42] Moon, M. J., "E-procurement management in state governments: Diffusion of e-procurement practices", Journal of Public Procurement, 5, 1 (2005), pp. 54-72.

[43] Nabafu, R. and G. Maiga., "A Model of Success Factors for Implementing Local E- government in Uganda", Electronic Journal of Electronic Government, 10, 1 (2012), pp. 31-46.

[44] Ndou, V., "E-government for developing countries: Opportunities and challenges", The Electronic Journal of Information Systems in Developing Countries, 18, 1 (2004), pp. 1-24.

[45] Nelson, K. L., and Svara, J. H., "Form of government still matters: Fostering innovation in US municipal governments", The American Review of Public Administration, 42, 3 (2012), pp. 257-281.

[46] Norris, D. F., and Reddick, C. G., "Local e-government in the United States: Transformation or incremental change?", Public Administration Review, 73, 1 (2013), pp. $165-175$. 
[47] Nu'man, A., "A framework for adopting e-voting in Jordan", Electronic Journal of e-Government, 2, 2 (2012), pp. 133-146.

[48] Nyirenda, J. C. and R. A. Cropf., "The Prospects for eGovernment and eGovernance in Sub- Saharan Africa: A Case Study of Zambia", International Journal of Electronic Government Research, 6, 1 (2010), pp. 2345.

[49] Panda, P., and Sahu, G. P., "e-Procurement Implementation: Critical Analysis of the Impact of Success Factors on Project Outcome", IUP Journal of Supply Chain Management, 9, 2 (2012), pp. 44-72.

[50] Parajuli, J., "A content analysis of selected government web sites: A case study of Nepal", The Electronic Journal of e-Government, 5, 1 (2007), pp. 87-94.

[51] Pekkanen, R., "Molding Japanese civil society: Statestructured incentives and the patterning of civil society", The state of civil society in Japan, (2003), pp. 116-134.

[52] Rogers, E.M., Diffusion of Innovations, 5th ed., Free Press, New York, NY, 2003.

[53] Rose, W. R., and Grant, G. G., "Critical issues pertaining to the planning and implementation of EGovernment initiatives", Government Information Quarterly, 27, 1 (2010), pp. 26-33.

[54] Sapat, A., "Devolution and innovation: The adoption of state environmental policy innovations by administrative agencies", Public Administration Review, 64, 2 (2004), pp. 141-151.

[55] Schwester, R. W., "Examining the Barriers to eGovernment Adoption", Electronic Journal of eGovernment, 7, 1 (2009), pp. 113-122.

[56] Scott, R.W., Institutions and organisations, Thousand Oaks, CA: Sage, 2008.

[57] Sobaci, M. Z., and Eryigit, K. Y., "Determinants of edemocracy adoption in Turkish municipalities: An analysis for spatial diffusion effect", Local Government Studies, 41, 3 (2015), pp. 445-469.

[58] Svidronova, M. M., and Nemec, J., "E-Procurement in Self-Governing Regions in Slovakia", Lex Localis, 14, 3 (2016), pp. 321.

[59] Teo, T. S. H., Lin, S., and Lai, K. Hung., "Adopters and non-adopters of e-procurement in Singapore: An empirical study", Omega, 37, 5 (2009), pp. 972-987.

[60] Tseng, P. T., Yen, D. C., Hung, Y. C., and Wang, N. C., "To explore managerial issues and their implications on e-Government deployment in the public sector: Lessons from Taiwan's Bureau of Foreign Trade", Government Information Quarterly, 25, 4 (2008), pp. 734-756.

[61] Urciuoli, L., Hintsa, J., and Ahokas, J., "Drivers and barriers affecting usage of e-customs: A global survey with customs administrations using multi- variate analysis techniques", Government Information Quarterly, 30 (2013), pp. 473-485

[62] Veit, D. J., Parasie, N. P., and Huntgeburth, J. C., "EProcurement Adoption at the Municipal Level: Influence of Organizational, Technological and Environmental Factors", In System Sciences (HICSS), 2011 44th Hawaii International Conference on (pp. 110) (2011, January), IEEE.
[63] Walker, R. M., Avellaneda, C. N., and Berry, F. S., "Exploring the diffusion of innovation among high and low innovative localities: a test of the Berry and Berry model", Public Management Review, 13, 1 (2011), pp. 95-125.

[64] Wang, S., and Feeney, M. K., "Determinants of information and communication technology adoption in municipalities", The American Review of Public Administration, 46, 3 (2016), pp. 292-313.

[65] Yin, R. K., Case study research: Design and methods. Sage publications, 2013.

[66] Yun, H. J., and Opheim, C., "Building on success: the diffusion of e-government in the American states", Electronic Journal of e-Government, 8, 1 (2010), pp. 71-82.

[67] Zhu, X., "Mandate versus championship: Vertical government intervention and diffusion of innovation in public services in authoritarian China”, Public Management Review, 16, 1 (2014), pp. 117-139. 